Published in final edited form as:

Chem Mater. 2019 November 12; 31(21): 8977-8986. doi:10.1021/acs.chemmater.9b03141.

\title{
Conformal Ultrathin Film Metal-Organic Framework Analogues: Characterization of Growth, Porosity, and Electronic Transport
}

\author{
Jonathan Lau ${ }^{\dagger}$, Ashley E. Trojniak ${ }^{\S}$, Macy J. Maraugha§, Alyssa J. VanZanten ${ }^{\S}$, Alexander J. \\ Osterbaan $^{\S}$, Andrew C. Serino ${ }^{\dagger}$, Monica L. Ohnsorg ${ }^{\S}$, Kevin M. Cheung ${ }^{\ddagger}, \#$, David S. Ashby ${ }^{\dagger}$, \\ Paul S. Weiss ${ }^{\dagger, \ddagger}, \#$, Bruce S. Dunn ${ }^{\dagger, \#}$, Mary E. Anderson ${ }^{\S, \neq,{ }^{*}}$ \\ † Department of Materials Science and Engineering, University of California, Los Angeles, Los \\ Angeles, California 90095, United States \\ ‡ Department of Chemistry and Biochemistry, University of California, Los Angeles, Los Angeles, \\ California 90095, United States \\ \# California NanoSystems Institute, University of California, Los Angeles, Los Angeles, California \\ 90095, United States \\ $\S$ Department of Chemistry, Hope College, Holland, Michigan 49423, United States \\ ¥ Department of Chemistry, Furman University, Greenville, South Carolina 29613, United States
}

\section{Abstract}

Thin-film formation and transport properties of two copper-paddlewheel metal-organic framework (MOF) -based systems (MOF-14 and MOF-399) are investigated for their potential integration into electrochemical device architectures. Thin-film analogs of these two systems are fabricated by the sequential, alternating, solution-phase deposition of the inorganic and organic ligand precursors that result in conformal films via van der Merwe-like growth. Atomic force microscopy reveals smooth film morphologies with surface roughnesses determined by the underlying substrates and linear film growth of 1.4 and $2.2 \mathrm{~nm}$ per layer for the MOF-14 and MOF-399 systems, respectively. Electrochemical impedance spectroscopy is used to evaluate the electronic transport properties of the thin films, finding that the MOF-14 analog films demonstrate low electronic conductivity, while MOF-399 analog films are electronically insulating. The intrinsic porosities of these ultrathin MOF analog films are confirmed by cyclic voltammetry redox probe characterization using ferrocene. Larger peak currents are observed for MOF-399 analog films compared to MOF-14 analog films, which is consistent with the larger pores of MOF-399. The layer-by-layer deposition of these systems provides a promising route to incorporate MOFs as thin films with nanoscale thickness control and low surface roughness for electrochemical devices.

\footnotetext{
*Corresponding Author: maryelizabeth.anderson@ furman.edu.

The authors declare no competing financial interest.

Supporting Information

The Supporting Information is available free of charge on the ACS Publications website.

Crystal structures of HKUST-1, MOF-399, MOF-143, and MOF-14, AFM image of gold substrate structure, schematic and data of selective etching process, AFM images of MOF-14 and MOF-399 films on methyl-terminated SAMs, AFM \& IR spectra of heattreated MOF-14 samples, EIS and XPS of MOF films, redox probe characterization calibration, redox probe characterization of MOF-399 films (PDF)
} 


\section{Graphical Abstract}

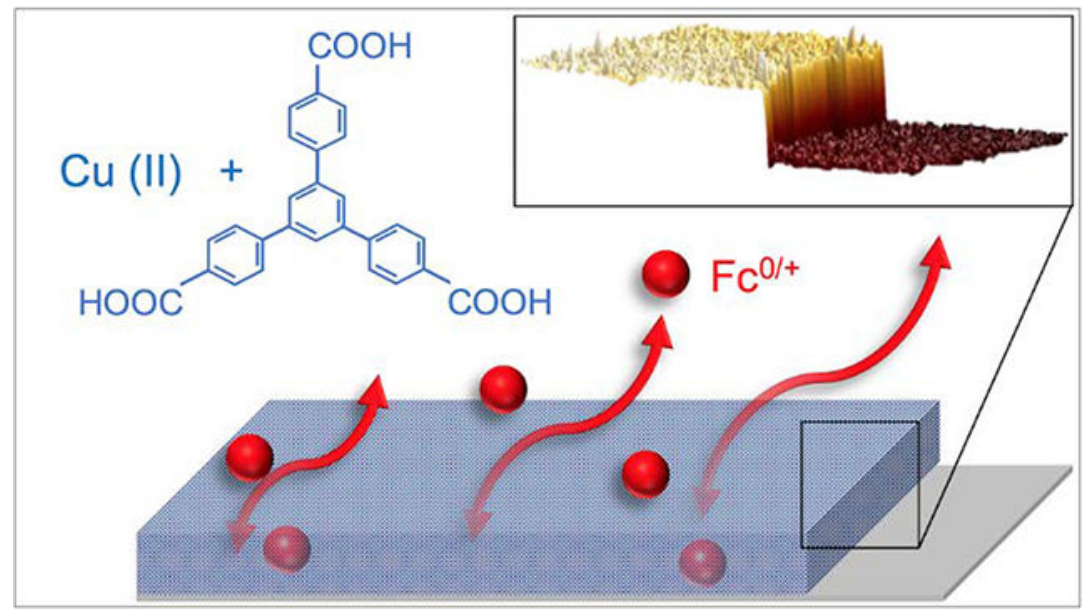

\section{INTRODUCTION}

Metal-organic frameworks (MOFs) are composed of metal ions (or clusters) and organic ligands coordinated to form porous one-, two-, or three-dimensional structures. The high surface areas of these materials has led to their extensive exploration for a variety of gasphase applications including storage. ${ }^{1}$ The porous structures are particularly relevant for electronic applications with MOFs as active or passive interfacial components as sensors ${ }^{2}$ or low-k dielectrics. ${ }^{3}$ Conductive MOFs can also be modulated by tailoring the internal chemical structure or by integration of analytes within the pores while nonconductive MOFs can serve as scaffolds for the transfer, separation, or storage of electroactive analytes without interfering with electronic transport. 4,5

In electrochemical energy storage applications, MOFs have been used as electrode materials for supercapacitors and batteries via redox of their mixed valence metal centers ${ }^{6}$ or organic groups. ${ }^{7}$ The intrinsic porosity and the ability to tailor pore sizes of MOFs has led to their application as molecular separators in lithium-sulfur batteries to prevent polysulfide shuttling. ${ }^{8}$ These intriguing properties have most recently led to the exploration of MOFs as frameworks for pseudo-solid-state electrolytes. Anions from lithium salts bind to the metal ions in MOFs and form ionic channels for lithium ions, resulting in ionic conductivities as high as $10^{-4} \mathrm{~S} \mathrm{~cm}^{-1}{ }^{9-11}$ While these values are only roughly equal to those of commercial separators, ${ }^{12}$ the higher lithium transference numbers observed in these pseudo-solid-state electrolytes due to the reduced anionic contribution portend to increased rate performance in electrochemical energy storage devices. ${ }^{10,11}$

The MOF-based pseudo-solid-state electrolytes are extremely promising for microscale electrochemical energy storage devices (e.g., thin-film batteries). The ability to harness liquid-phase kinetics without introducing difficulties in device packaging offers substantial improvements over traditional solid electrolytes such as LiPON (ionic conductivity $\sim 10^{-6} \mathrm{~S}$ $\left.\mathrm{cm}^{-1}\right) .{ }^{13}$ However, the synthesis of MOFs through the spontaneous reaction of precursors in solution is unsuitable for microscale devices that require precise control over deposition area 
and thickness. Additionally, the random growth of MOF crystallites on substrates may lead to disordered porosity and grain structure that can impede ion diffusion. This result is problematic in solid-state electrolytes as it can lead to uneven fluxes of lithium and the under-utilization of electrode materials. ${ }^{14}$

For integration into device architectures, surface-anchored metal-organic frameworks (SurMOFs) can be deposited directly onto electrodes. ${ }^{15-24}$ Metal-organic coordination offers control over the layer-by-layer (LbL) assembly of metal-organic multilayers with sequential deposition of metal and organic components on a functionalized surface, permitting the atomic control of film structure and composition. ${ }^{25-33}$ An advantage of this deposition technique is the ability to fabricate highly ordered films that can be preferentially oriented to facilitate ionic conduction. While the self-limiting nature of the LbL process enables precise control of films deposited directly on electrodes, the film quality is highly dependent on growth mechanism. The LbL deposition of most SurMOFs systems (e.g., HKUST-1, $\mathrm{Cu}_{2}\left(\mathrm{~F}_{4} \mathrm{bdc}\right)_{2}$ (dabco), and ZIF-8) $)^{15,18,23}$ is controlled by Volmer-Weber growth. This mechanism is reflected in the nucleation of isolated crystallites that lead to rough surfaces with respect to the substrate. Typically, it is not until several tens of rounds of LbL deposition or film thicknesses greater than $50 \mathrm{~nm}$ that coverage of the substrate with the granular film is complete. Conversely, the LbL deposition of SurMOF systems via van der Merwe growth, resulting in conformal film growth, is strongly desired for the direct integration of MOF thin films onto technologically relevant substrates or into device architectures such as electrodes for microscale energy storage devices.

Herein, the formation of ultrathin film analogs of MOF-14 and MOF-399 are demonstrated and shown to form mechanistically via van der Merwe-like growth with film roughnesses defined by the underlying substrates and tailorable film thickness at the nanoscale. The films are deposited on functionalized Au substrates, and the film morphologies and thicknesses are characterized by atomic force microscopy. Different substrates and self-assembled monolayers (SAMs) for anchoring the MOFs are investigated to test the hypothesized growth mechanism and to determine if film formation can be translated to other functionalized, technologically relevant substrates. ${ }^{34-37}$

The MOF-14 and MOF-399 structures are related to the iconic HKUST-1 system, as they are composed of copper-paddlewheel nodes with tritopic ligands (Figure S1). Since MOF-14 and MOF-399 have larger organic linkers than HKUST-1, their pore sizes of 1.6 and $4.3 \mathrm{~nm}$ and unit cells of $2.7 \mathrm{~nm}$ and $6.8 \mathrm{~nm}$, respectively, are larger. The density of MOF-399 at 0.13 $\mathrm{g} \mathrm{cm}^{-1}$ is also one of the lowest amongst MOF systems. MOF-14 has an interwoven pto topology that differs from the tbo topology observed for HKUST-1 and MOF-399. ${ }^{38}$

In this work, conformal ultrathin film analogs of MOF-14 and MOF-399 are studied with thicknesses between 5 and $40 \mathrm{~nm}$, which are less than 10 unit cells. To elucidate the internal structures of these films, the porosities are evaluated by cyclic voltammetry utilizing redox probes in a manner similar to previous evaluation of HKUST-1 SurMOFs. ${ }^{39,40}$ We hypothesize that the larger pore sizes of MOF-14 and MOF-399 relative to HKUST-1 may result in higher ionic conductivities when used as frameworks for pseudo-solid-state 
electrolytes. Toward this determination, we use electrochemical impedance spectroscopy to investigate electron transport in these films.

\section{EXPERIMENTAL SECTION}

\section{Materials}

1,3,5-tris(4-carboxyphenyl)benzene [BTB] (98\%), 1,3,5-tris(4'carboxy[1,1'-biphenyl]-4yl)benzene [BBC] (95\%), copper (II) acetate monohydrate, 16-mercaptohexadecanoic acid [MHDA] (90\%), 11-mercapto-1-undecanol [MUD] (97\%), 1-octadecanethiol [ODT] (98\%), hydrochloric acid (ACS reagent, 37\%), anhydrous propylene carbonate [PC], and anhydrous dimethyl sulfoxide [DMSO] are from Sigma Aldrich (St. Louis, MO). Absolute, anhydrous ethanol (200 proof, ACS/USP Grade) was obtained from Phamco-Aaper (Shelbyville, KY). These chemicals were used as received. Ferrocene ( $\mathrm{Fc}$, Sigma Aldrich) and tetrabutylammonium tetrafluoroborate (TBATFB, Sigma Aldrich) were dried at $120{ }^{\circ} \mathrm{C}$ under vacuum for $12 \mathrm{~h}$ prior to transferring to an Ar-filled glovebox (less than $1 \mathrm{ppm} \mathrm{O}_{2} /$ $\mathrm{H}_{2} \mathrm{O}$ ). Silicon wafers with a $5 \mathrm{~nm}$ Ti adhesion layer and a $100 \mathrm{~nm}$ Au layer were obtained from Platypus Technologies (New Orleans, LA). Ge (100) wafers were obtained from MTI Corporation (Richmond, CA).

\section{Thin Film Formation}

Thin films based on the coordination of MOF-14 and MOF-399 were fabricated on a selfassembled monolayer (SAM) -functionalized Au substrates using alternating, solution-phase depositions. The substrates were first immersed in a $1 \mathrm{mM}$ MHDA ethanolic solution for $1 \mathrm{~h}$ to fabricate a SAM that anchors the MOF analog to the Au substrate. The substrates were removed from solution, rinsed thoroughly with ethanol, and dried under $\mathrm{N}_{2}$. An automated deposition system (Midas III-Plus Automated Slide Stainer) was used to deposit MOF components. The substrates were submerged for $30 \mathrm{~min}$ in a $1 \mathrm{mM}$ ethanolic solution of $\mathrm{Cu}\left(\mathrm{C}_{2} \mathrm{H}_{3} \mathrm{O}_{2}\right)_{2}$. Then, the substrates were submerged in a $0.1 \mathrm{mM}$ ethanolic solution of $\mathrm{BBC}$ or BTB for $1 \mathrm{~h}$. After the deposition of each inorganic and organic component, the substrates were agitated in pure ethanol for $5 \mathrm{~min}$, after which they were dried at $30^{\circ} \mathrm{C}$ for $10 \mathrm{~min}$. This process was repeated for the desired number of deposition cycles. Prior to electrochemical characterization, MOF-14- and MOF-399-based samples were dried using a Schlenk line at $130{ }^{\circ} \mathrm{C}$ and $10^{-2}$ Torr for at least $2 \mathrm{~h}$ to remove any residual solvent or ambient water.

\section{Monolayer Deposition on Ge}

For samples synthesized on Ge substrates, a different SAM preparation was used as reported in the literature. ${ }^{41}$ To remove the oxide layer from the Ge surface, samples were submerged in DI water for $1 \mathrm{~min}$ and dried under $\mathrm{N}_{2}$. A 1:1 solution of ethanol in water was used to make a $0.5 \mathrm{mM}$ MHDA solution. The Ge substrate was then immersed in the solution for 1 hour, dried under $\mathrm{N}_{2}$, and placed on the deposition system for the desired number of layers as described above. 


\section{Atomic Force Microscopy (AFM)}

A Dimension Icon Atomic Force Microscope (Bruker, Santa Barbara, CA) operating in peak force tapping mode was used to obtain a minimum of two $500 \mathrm{~nm}$ images $(512 \times 512$ pixels $)$ per sample. Etched SiN tips, SCANASYST-AIR (Bruker, Santa Barbara, CA), with spring constants of $0.2-0.8 \mathrm{~N} \mathrm{~m}^{-1}$ and resonant frequencies of $45-95 \mathrm{kHz}$ were used. Scan parameters were as follows: $1 \mathrm{~Hz}$ scan rate, $12 \mu \mathrm{m}$ z-range, $250-370 \mathrm{mV}$ amplitude setpoint, and $100-450 \mathrm{mV}$ drive amplitude. Using the NanoScope Analysis software (Bruker, Santa Barbara, CA), all $500 \mathrm{~nm}$ images were plane fitted and the color scale was set uniformly to be $10 \mathrm{~nm}$. Nanoscope Analysis software (Bruker) was used to analyze the images and determine the surface roughness, Rq.

\section{Infrared Spectroscopy (IR)}

A Nicolet iS50 instrument (Thermo Scientific) was used to collect IR spectra from 3800-600 $\mathrm{cm}^{-1}$ in ATR (Attenuated Total Reflectance). Spectra were collected at a resolution of $4 \mathrm{~cm}^{-1}$ over a set of 64 scans and a bare Au substrate was used for background subtraction.

\section{Ellipsometry}

A variable angle discreet wavelength ellipsometer (PHE-101 VADE, Angstrom Advanced, Braintree, MA) was used for routine characterization of the films. Data were acquired for each sample over a minimum of six spots at a wavelength of $632.8 \mathrm{~nm}$ and a fixed angle of $70^{\circ}$.

\section{Film Thickness}

To determine film thickness, an area of the film was etched to provide a step edge for characterization of the film height relative to the substrate as measured by AFM. A region of the film was masked with cellulose tape and the entire sample was submerged for $1 \mathrm{~min}$ in 1 $\mathrm{M} \mathrm{HCl}$. Upon removal from the etchant, the sample was rinsed with water and ethanol before drying under $\mathrm{N}_{2}$. After removal of the tape, etched and masked regions of the substrate were characterized using ellipsometry. Comparison of ellipsometry measurements before and after etching confirmed the removal of the film from the exposed region and showed that the masked region of the film remained unaffected. AFM images were collected at the step edge of the film created by the etch for a minimum of three regions per samples for two different deposition batches. Nanoscope Analysis software (Bruker) was used to calculate the film thickness from the average heights of the film and substrate regions where the film was removed.

\section{X-ray Photoelectron Spectroscopy (XPS)}

$\mathrm{X}$-ray photoelectron spectra were recorded with a Kratos Axis Ultra using a monochromatic $\mathrm{Al} \mathrm{X}$-ray source to probe the surface of the sample and to determine the presence and valence of $\mathrm{Cu}$ in the films. Peak calibration was performed using the adventitious carbon peak. Analysis was performed before and after $10 \mathrm{~nm}$ Ar etching. 


\section{Electrochemical Impedance Spectroscopy (EIS)}

Electrochemical impedance spectra were measured using a Solartron 1252A 1252A

Frequency Response Analyzer and 1287A Potentiostat Galvanostat. Measurements were recorded from $100 \mathrm{kHz}$ to $100 \mathrm{~Hz}$ using a $10 \mathrm{mV}$ RMS potential with zero bias from the open circuit potential. Electrical contact to the film was made via a clip to the Au substrate and a hanging mercury drop electrode [HMDE] in direct contact to the film. ${ }^{42}$ Impedance spectra of the MOF-14 analog film were fit to an equivalent circuit using ZView software (Scribner) in order to calculate the electronic conductivity of the material. Error bars were calculated using a range of HMDE contact areas (from 1-3 mm in diameter) that can vary depending on the distance between the HMDE and the sample.

\section{Cyclic voltammetry}

Electrochemical porosity was determined in three-electrode cells in an Ar-filled glove box using a Bio-Logic VMP-3 potentiostat. Platinum electrodes were used as counter and quasireference electrodes. A solution of $10 \mathrm{mM} \mathrm{Fc} \mid 100 \mathrm{mM}$ TBATFB in PC was used as the redox probe electrolyte. Cyclic voltammetry was performed at a sweep rate of $10 \mathrm{mV} \mathrm{s}^{-1}$ from -0.4 to $0.8 \mathrm{~V}$ vs the quasi-reference electrode $( \pm 0.6 \mathrm{~V}$ from the oxidation potential of Fc determined by calibration using a bare Au substrate).

\section{RESULTS AND DISCUSSION}

\section{Characterization of Film Growth Mechanism}

To elucidate the film growth mechanisms for MOF-14 and MOF-399 analogs, films were deposited onto carboxylic-acid-terminated SAMs on Au substrates. Samples were characterized by AFM and IR spectroscopy after every four deposition cycles of the MOF components. Atomic force microscopy was used to characterize film morphology, roughness, and thickness. Infrared spectroscopy was used to test film deposition and chemical composition. To explore the film growth, the deposition was studied on hydroxyland methyl-terminated SAMs on Au substrates as well as on carboxylic-acid-terminated Ge substrates. To explore the film growth, the deposition was studied on hydroxyl- and methylterminated SAMs on Au substrates as well as on carboxylic-acid-terminated Ge substrates.

The MOF analog films were anchored on thermally deposited Au substrates, which have a "cobblestone-like" grain structure (50-100 nm diameter) and roughness (Rq) of $1.5 \mathrm{~nm}$ (Figure S2). After four layers of deposition, the underlying Au cobblestone structure was observed with overlying smaller bulbous features from the film (Figure 1). The presence of the Au grain structure after film deposition indicates that the resulting film is conformal with the underlying substrate structure. Over an increasing number of deposition cycles, the AFM images continue to show similar morphological structures, but the underlying cobblestone features become less prominent. Note that the lessening of the cobblestone features occurs sooner for the MOF-399-based film, as expected, due to the larger size of the BBC linker for the MOF-399 system compared to the BTB linker for the MOF-14 system.

To test if the changes in morphological features are correlated to film deposition, IR spectroscopy (Figure 2) was performed after every four deposition cycles. Linear increases 
in the IR peak areas were observed with increasing numbers of deposition cycles, confirming the deposition of additional material. This result indicates that the film continues to conform to the substrate and produces the consistent morphological features observed via AFM.

The morphological features observed via AFM and the increase in signal in the IR spectroscopic data support a van der Merwe-like growth mechanism for the film, layer-bylayer film growth with the alternating, solution-phase deposition. To investigate film formation quantitatively, the physical thickness of the film was determined by selectively etching a region of the film and then performing AFM at step edges (Figure S3). The film thicknesses and standard deviations are plotted in Figure 3a for multiple samples from different deposition batches. For both systems, highly linear film growth is observed, and linear fitting yields $\mathrm{R}^{2}$ values of 0.9981 and 0.9992 for the deposition of MOF-14 and MOF-399 chemistries, respectively. Notably, the MOF-399 analog, with its larger organic linker, increases $2.2 \mathrm{~nm}$ per layer while the MOF-14 analog increases $1.4 \mathrm{~nm}$ per layer. These results are consistent with van der Merwe-like growth and demonstrate that nanometer-scale control of film thickness is possible. Additionally, roughness (Rq) measurements for all films are reproducibly low and consistent with the roughness of the underlying Au substrates (Figure 3b).

The growth mechanism observed for MOF-14 and MOF-399 is different than what is observed for the related copper-paddlewheel HKUST-1 system. Under identical deposition conditions, HKUST-1 was found to grow via Volmer-Weber growth in which the nucleation and growth of isolated crystallites are independent of the underlying Au substrate morphology. While it was expected that the copper-paddlewheel node present in all three systems determines the mechanism of film growth, this result was not observed. Additionally, the different crystal topology of HKUST-1 and MOF-399 versus MOF-14 (tbo vs pto) does not differentiate the mechanism of film formation. We attribute the different solubilities of the organic ligands in the ethanolic deposition solutions as the likely determining factor. The organic ligands are decreasingly soluble from HKUST-1 to MOF-14 to MOF-399 due to increased $\pi-\pi$ stacking. In the case of the HKUST-1, the small organic linker favorably interacts with both the substrate and solvent, enabling the interplay between binding and solvation needed to create crystallite islands. In the case of MOF-14 and MOF-399 systems, low solubilities favor surface binding and limit reorganization of the organic linkers at the substrate-solvent interface. Surface binding of the organic ligands continues across the substrate until coordination with the copper paddlewheel nodes are saturated. This process is repeated after immersion of the films in the solution of metal ions to introduce additional surface sites leading to conformal films through the LbL, van der Merwe-like growth mechanism.

Note that both MOF-14 and MOF-143 are composed of the same inorganic and organic components. Interpenetration of the network is observed in MOF-14, resulting in increased density and decreased pore size relative to MOF-143 (Figure S1c,d). MOF-14 is more commonly observed than MOF-143 because MOF-143 is only formed under careful control of concentration and conditions. ${ }^{38}$ The differences observed with electrochemical 
characterization, including the presence of electronic conductivity (vide infra), also suggest coordination resembling that of the MOF-14 system.

To further investigate the growth mechanism of MOF-14- and MOF-399-based films, both systems were deposited on hydroxyl-terminated and methyl-terminated SAMs on Au substrates. Film growth consistent with that of the carboxylic-acid-terminated SAMs shown in Figure 1 was observed for the hydroxyl-terminated MUD SAMs (Figure 4a and 4b), but not for the methyl-terminated ODT SAMs (Figure S4). The importance of the functional group in anchoring the films to the substrate is consistent with the role of the functional group observed in the binding of the HKUST-1 system. ${ }^{18}$ The differences in the film growth observed on the carboxyl- and hydroxyl-terminated SAMs compared to the methylterminated SAM confirms that the film deposition described in this study is due to the complexation of copper ions with the hydrophilic carboxyl and hydroxyl groups. The differences in film growth on the methyl-terminated SAMs suggest that film formation for the MOF-14 and MOF-399 analogs is not due to the non-specific physisorption of the organic molecules.

Additionally, the film formation of MOF-14 and MOF-399 analogs on Ge(100) substrates was studied utilizing SAM deposition for functionalized alkanethiols that eliminates the native oxide while the anchoring layer is assembled. ${ }^{41}$ Oxide formation has hindered the incorporation of Ge into device architectures, yet the development of surface passivation methods enables the functionalization of the interface for relevant applications. ${ }^{41,43,44}$ Atomic force microscopy measurements for these MOF films on Ge (Figure $4 \mathrm{c}$ and $4 \mathrm{~d}$ ) revealed the same small bulbous features as observed for the films on Au. These results further support that the small morphological features are intrinsic to the films as they are also observed atop the larger cobblestone structures for the Au substrate. Additionally, the film roughness below $1 \mathrm{~nm}$ observed for the MOF-based films on Ge substrates highlights the smooth, conformal nature of these ultrathin films. These data also demonstrate that these films can be translated to technologically relevant substrates for a multitude of uses (i.e., Ge can be used in semiconductor and electrochemical energy storage applications). ${ }^{45,46}$ The ability to control the deposition of SurMOF thin films precisely is particular promising for thin-film batteries in which the thickness of the solid electrolyte can be up to 20 times the thickness of the alloying anode (e.g., $1 \mu \mathrm{m}$ compared to $50 \mathrm{~nm}$ of $\mathrm{Sn}, \mathrm{Si}, \mathrm{Ge}$, etc.) and can be a limiting factor in the energy density of the device. ${ }^{47}$ The constraint of the active material films by the current collector ${ }^{48}$ can also help to ensure that the ultrathin MOF analog films remain anchored to the material during electrochemical cycling.

Thin-film characterization reveals well-behaved smooth and conformal films assembled from MOF inorganic and organic components utilizing alternating solution-phase deposition methods. The resulting films have film thicknesses that can be controlled at the nanoscale, generating $1.4 \mathrm{~nm}$ and $2.2 \mathrm{~nm}$ of film per deposition cycle for the MOF-14- and MOF-399based systems, respectively. For perspective, MOF-14 and MOF-399 have cubic lattice parameters of $2.7 \mathrm{~nm}$ and $6.8 \mathrm{~nm}$, respectively. ${ }^{38}$ It is hypothesized that each deposition cycle in the MOF-14-based system produces one-half a unit cell and each deposition cycle in the MOF-399-based system produces one-third of a unit cell (Figure S5). The increases in film thickness per deposition cycle correlate with the dimensions of the respective tritopic 
ligands. The BTB ligand in the MOF-14 system has a triangular edge of $1.3 \mathrm{~nm}$ and the BTC ligand in the MOF-399 system has an edge length of $2.1 \mathrm{~nm}$.

However, the internal structure and long-range periodicity of these films is difficult to probe, as after 16 deposition cycles, the resulting films are $20.9 \pm 1.1 \mathrm{~nm}$ and $34.5 \pm 1.9 \mathrm{~nm}$ thick for the MOF-14- and MOF-399-based systems, respectively. Based on the unit cells dimension for MOF-14 and MOF-399 $(2.7 \mathrm{~nm}$ and $6.8 \mathrm{~nm}),{ }^{38}$ even the thickest films are only 7 or 5 unit cells in thickness, respectively. At this thickness scale, characterization by traditional laboratory X-ray diffraction techniques is not feasible (confirmed experimentally, data not shown) and crystal structure characterization will require specialized techniques involving synchrotron radiation sources.

Thus, to investigate the porosity of these films and preliminarily demonstrate their viability as frameworks for pseudo-solid-state electrolytes, electrochemical impedance spectroscopy and cyclic voltammetry using a redox probe electrolyte were performed.

\section{Electrochemical Characterization}

Low electronic conductivities and large porosities are desirable qualities for MOF films as pseudo-solid-state electrolytes in microscale electrochemical energy storage devices. Electronically insulating frameworks minimize leakage currents through the pseudo-solidstate electrolyte, resulting in minimal self-discharge of devices. Meanwhile, a large freevolume maximizes the amount of liquid electrolyte accommodated in the framework, resulting in large ionic conductivities. We used electrochemical impedance spectroscopy and redox probe characterization to determine the electronic transport properties and porosity, respectively, in these MOF-14- and MOF-399-based films.

To assess the viability of using these films as pseudo-solid-state electrolytes, the electronic transport properties of the materials were characterized using EIS. Impedance spectra of MOF-14 and MOF-399 analog films, representative of the average shape and impedance values of several spectra, are shown in Figure 5a and 5b. The Nyquist plot of the MOF-14 analog film impedance shows semi-circular behavior characteristic of transport phenomena, while the MOF-399 analog film behaves like an insulating dielectric material. Impedance spectra for these samples were generally consistent across multiple positions of the films sampled using the HMDE.

Based on previous reports investigating the electron transport of HKUST-1, MOF-14 is expected to be an electronic insulator ${ }^{49,50}$ and modest proton conductor (on the order of $1 \mu \mathrm{S}$ $\left.\mathrm{cm}^{-1}\right) .{ }^{50,51}$ Heat treatment of our ultrathin MOF analog samples to remove residual water prior to electrochemical characterization is known to reduce the likelihood of proton conduction in these films. The removal of water by heating the MOF-14-based films was confirmed by FTIR (Figure S6). However, the transport phenomena persisted in these samples, and it is hypothesized that the measured impedance is electronic conduction in the MOF-14 analog films.

HMDEs have been demonstrated to make robust electrical contact to polymer films ${ }^{52}$ and $\mathrm{MOFs}^{40}$ without introducing large contact resistances. The magnitudes of the measured 
resistances also exclude the possibility of electronic shorting of the HMDE to the current collector through defects in the MOF analog films as this would result in low resistances $<1$ $\Omega$ (Figure S7). These nanoscale thick MOF-14 and MOF-399 analog films have detectable electronic conductivities within the limits of the instruments. The impedance spectra from multiple EIS measurements (Figure S8) were fit to the equivalent circuit shown in Figure 5 (inset) and the average parallel resistance was used to calculate an electronic conductivity of $2.9 \pm 2.8 \times 10^{-8} \mathrm{~S} \mathrm{~cm}^{-1}$ for $8 \mathrm{~L}$ MOF-14 analog film ( 10 nm in thickness).

To test this hypothesis of electronic conduction in MOF-14-based films, samples were exposed to DMSO vapor under vacuum after heat treatment. DMSO has a strong affinity for copper metal ions compared to water or ethanol ${ }^{53,54}$ and is expected to displace any residual water that, while unlikely, may remain in the film after heating. It was found that the electronic conductivity of the MOF-14 analog films after DMSO treatment does not change $\left(2.9 \pm 2.9 \times 10^{-8} \mathrm{~S} \mathrm{~cm}^{-1}\right)$ (Figure S9).

Most MOFs, with the notable exception of frameworks that utilize "through bond" or "through space" strategies to improve electronic conductivity, are wide band gap insulators. 4,5 As in HKUST-1, the porosity of MOFs leads to highly localized orbitals and the absence of charge delocalization. ${ }^{55}$ Thus, electronic conduction is likely to occur through electron hopping rather than band transport. The incorporation of redox-active molecules into the porous structure can enhance conduction through this mechanism by increasing the number of hopping sites. ${ }^{51}$ Electron hopping through redox mediation has also been identified as the mechanism of conduction in MOFs containing metalloporphyrins ${ }^{56}$ as well as in semiconducting ceramics ${ }^{57}$ and glasses. ${ }^{58}$ The RC time constant for electron hopping in MOF-14 from EIS is $\sim 10^{-3} \mathrm{~s}$ and agrees well with values reported for these materials $\left(10^{-3}-10^{-5} \mathrm{~s}\right)$. 59,60

For ultrathin films based on MOF-14 and MOF-399 chemistries, the $\mathrm{Cu}^{+/ 2+}$ metal sites are hypothesized to undergo oxidation/reduction enabling electronic conduction in the samples, and XPS (Figure S10) indicates the presence of both $\mathrm{Cu}^{+}$and $\mathrm{Cu}^{2+}$ in MOF-399 analog films. The presence of $\mathrm{Cu}^{+}$and $\mathrm{Cu}^{2+}$ is also expected in MOF-14-based samples due to the use of identical synthesis methods. While the presence of electronic conductivity in the MOF-14-based film is somewhat unexpected, the dielectric behavior of MOF-399 is not. Unfortunately, accurate DC measurement of the electronic conductivity of MOF-399-based film proved difficult due to high resistance and low signal-to-noise ratios. However, the large pore sizes in MOF-399 equate to increased distances between hopping sites and should result in more tortuous pathways for electronic conduction. The different topologies of MOF-14 and MOF-399 (Figure S1) may also be a factor in the contrasting electrical behaviors of these materials as the high $\mathrm{Cu}^{+/ 2+}$ density in the interwoven pto structure of the related MOF-14 structure may make electron hopping more facile in the MOF-14 analogs studied here.

Using MOFs for pseudo-solid-state electrolyte applications requires sufficiently large pores to accommodate the diffusion of ions and their respective solvation shells. While HKUST-1 (1.1 $\mathrm{nm}$ pore diameters) demonstrated suitable ionic conductivity $\sim 4 \times 10^{-4} \mathrm{~S} \mathrm{~cm}^{-1}$ at room temperature, the confinement of lithium ions resulted in high activation energies $\sim 0.18 \mathrm{eV}$ 
(compared to $0.10 \mathrm{eV}$ for liquid electrolytes). ${ }^{10}$ Larger pores are thus expected to allow a more complete solvation of ions and thereby to reduce the confinement effect.

Electrochemical characterization of MOF-14 and MOF-399 analog film samples in a redox probe electrolyte was used to demonstrate the intrinsic porosity of the films due to the difficulty of nitrogen sorption measurements on this nanoscale amount of film material. The presence of redox currents provides qualitative evidence that redox molecules are able to diffuse through the film to the surface of the Au current collector and undergo oxidation/ reduction. Similar studies have used ferrocene loaded via the vapor phase to demonstrate the porosity of MOFs using electrochemical, ${ }^{39}$ electrical, ${ }^{40}$ or physical characterization techniques. ${ }^{61}$ Prior to the porosity characterization of MOF-14 and MOF-399 analog films, cyclic voltammetry of the bare Au current collector in the $10 \mathrm{mM} \mathrm{Fc} 100 \mathrm{mM}$ TBATFB PC was used to characterize the Fc electrolyte. Measurements were performed from -0.4 to 0.8 $\mathrm{V}$ vs Pt using sweep rates from 1 to $50 \mathrm{mV} \mathrm{s}^{-1}$ (Figure S11). The calculated diffusion coefficient of Fc of $1.6 \times 10^{-6} \mathrm{~cm}^{2} \mathrm{~s}^{-1}$ agrees well with reported literature values ${ }^{62}$ and is consistent with a solvation shell diameter of $1.1 \mathrm{~nm}$ (see Supporting Information for details).

Cyclic voltammetry of MOF-14-based films (Figure 6a) displayed increases in current on the anodic sweep starting at the oxidation potential of Fc $(0.2 \mathrm{~V}$ vs $\mathrm{Pt}$ as measured using bare Au substrates). The sigmoidal voltammograms for MOF-14 analog films are indicative of convergent diffusion and are consistent with computational models for electrodes covered with an electroinactive film of uniform porosity. ${ }^{63}$ This result suggests that the redox of Fc occurs at small, widely spaced regions of Au current collector consistent with an array of microelectrodes. ${ }^{64,65}$ This condition is satisfied by the templated nature and intrinsic porosity of the SurMOF, with MOF-14 having a pore size $(1.6 \mathrm{~nm}),{ }^{38}$ slightly larger than the calculated solvation shell of Fc. The observation of sigmoidal voltammograms also suggests that Fc redox facilitated by the electronic conduction in MOF-14 analog films is negligible, as it would lead to the presence of redox peaks. The use of a redox probe electrolyte thus offers qualitative evidence of porosity in MOF-14-based films.

Cyclic voltammetry of MOF-399-based samples (Figure 6b) displayed similar behavior to MOF-14 analog samples with the onset of the increase in anodic current consistent with the oxidation potential of Fc. However, the voltammogram of the MOF-399 analog 8L thin film is notably different due to the presence of redox peaks. The shape of the voltammograms for a given sweep rate is heavily dependent on the radius and length of the pores in the electroinactive film. ${ }^{63}$ The large poreradius of MOF-399 $(4.3 \mathrm{~nm})^{38}$ relative to the thickness of the film for the MOF-399 analog 8L thin-film sample leads to the observation of redox peaks, which are indicative of planar diffusion to a macroelectrode. The increased pore lengths (and thus diffusion layer thicknesses) in the thicker MOF-399 analog 12L and 16L thin-film samples leads to the observation of sigmoidal voltammograms indicative of convergent diffusion, as observed in the MOF-14-based samples.

SAMs of alkanethiols are typically dense enough to suppress the redox reactions of probe molecules in solution. ${ }^{64,65}$ However, previous work has shown that the complexation of carboxylic acid functional moieties of alkanethiols by $\mathrm{Cu}^{2+}$ (as in the synthesis of the MOF analogs using MHDA) can lead to significant decreases in the densities of the underlying 
SAM. ${ }^{66}$ We hypothesize that this effect allows Fc to reach the surface of the current collector and undergo redox reactions. Similar electrochemical signals have been observed in the characterization of other surface-anchored MOF films with underlying MHDA SAMs using solution-based redox systems. ${ }^{39}$ Differences in the redox probe molecule, solvent of the redox system, and terminal group of the alkanethiol may also contribute to the observed redox activity through an enhanced chemical selectivity of the redox probe by the SAM. ${ }^{64,65}$

It is unlikely that macroscopic defects are responsible for the redox currents observed in the MOF analog films. The AFM measurements do not show the presence of macroscopic or microscopic defects, such as pinholes or cracks, and the MOF films do not show redox peaks at the formal potential of Fc ( $\sim 2 \mathrm{~V}$ vs Pt). In the case of the MOF-399 analog $8 \mathrm{~L}$ thin-film sample, the presence of redox peaks does not indicate the presence of macroscopic or microscopic defects. The separation of the redox peaks for the MOF-399 analog 8L thin-film sample $(\sim 0.55 \mathrm{~V})$ does not match the separation measured with the bare Au substrate $(\sim 0.2$ V) as would be expected for a bare current collector. The peak currents measured are also not proportional to the square-root of the sweep rate as predicted by the Randles-Sevcik equation (Figure S12), indicating that the Fc redox observed is not due to planar diffusion to macroelectrodes or macroscopic or microscopic defects. ${ }^{64}$ The approximately steady-state value observed at higher sweep rates is consistent with a transition from planar to convergent diffusion as predicted from computational modeling. ${ }^{63}$ This observation indicates that the currents are the result of redox reactions at microelectrodes that arise from the templated nature and intrinsic porosity of the MOF analog films.

The asymmetry observed in the voltammograms for MOF-14- and MOF-399-based samples across all thicknesses (including the large currents that are observed as the electrode approaches the upper voltage limit of $0.8 \mathrm{~V}$ ) is attributed to neutral molecules approaching the electrode surfaces more closely than charged molecules. This difference enables stronger electronic overlap with the electrode, resulting in higher measured currents. Similar screening and asymmetry for Fc redox in cyclic voltammetry was observed for HKUST-1. 39 The MOF-14- and MOF-399-based samples also show decreasing currents with increasing MOF thickness at the oxidation potential of Fc (Figures S13 and S14). Peak currents of 8.5, 3.9, and $3.3 \mu \mathrm{A}$ were measured for MOF-14 analog 8L, 12L, and 16L thin-film samples, respectively. Similarly, peak currents of 19.3, 8.9, and $6.4 \mu \mathrm{A}$ were measured for MOF-399 analog $8 \mathrm{~L}, 12 \mathrm{~L}$, and $16 \mathrm{~L}$ thin-film samples, respectively. These values are tabulated in Table $\mathrm{S} 1$ for ease of comparison. The decrease observed in the peak currents with increasing film thickness is consistent with computational models that predict that the steady-state redox current is inversely proportional to the pore length for a given pore radius. ${ }^{63}$

The demonstrated porosity of these ultrathin MOF analog films is promising for their potential application as frameworks for pseudo-solid-state electrolytes. The larger redox currents observed for the MOF-399-based samples indicate that transport is more facile in the larger pores of the framework compared to MOF-14-based samples. This difference promises increased ionic conductivities and reduced activation energies for conduction compared to other MOF-based pseudo-solid-state electrolytes. Most importantly, the increased porosity of MOF-399 analog thin-film samples results in the elimination of electronic conduction in the thin films, which is critical for pseudo-solid-state electrolyte 
applications. While MOF-14-based films are unsuitable for electrochemical energy storage applications due to the presence of electronic conduction, the potential for infiltrating redoxactive guest molecules such as 7,7,8,8-tetracyanoquinododimethane (TCNQ) to augment their conductivity may be useful in electronic devices. ${ }^{51}$

\section{CONCLUSIONS AND PROSPECTS}

Conformal ultrathin films based on MOF-14 and MOF-399 chemistries were fabricated via sequential, alternating, solution-phase deposition of the inorganic and organic components. On carboxylic-acid-functionalized Au substrates, these films were conformal and had low surface roughnesses of $\sim 1.5 \mathrm{~nm}$, on par with that of the Au substrates. Linear film growth was observed from the LbL deposition and deposition rates of $1.4 \mathrm{~nm}$ and $2.2 \mathrm{~nm}$ per layer were observed for the MOF-14 and MOF-399 systems, respectively. van der Merwe-like growth for the films was observed, in contrast to Volmer Weber growth found for the related copper-paddlewheel HKUST-1 system. This difference was likely due to the lower solubilities of the MOF-14 and MOF-399 organic linkers in the ethanolic deposition solutions that promotes surface-binding at the substrate-solvent interface. This mechanism was confirmed by comparable film formation on carboxylic-acid-functionalized $\mathrm{Ge}$ substrates and hydroxyl-functionalized Au substrates; as well as by the lack of film formation on the methyl-functionalized Au substrates.

Electrochemical impedance spectroscopy was performed to assess the viability of using MOF analog films as pseudo-solid-state electrolytes in microscale electrochemical energy storage devices. Nyquist plots of impedance spectra of MOF-14-based films were semicircular indicating transport phenomena $\left(2.9 \times 10^{-8} \mathrm{~S} \mathrm{~cm}^{-1}\right.$ for a $\sim 10 \mathrm{~nm}$ film). This impedance feature was retained after treatment with DMSO suggesting that it was electronic, rather than protonic, via electron hopping between $\mathrm{Cu}^{+/ 2+}$ sites. Conversely, MOF-399-based films showed purely dielectric behavior presumably due to the increased hopping distances due to the increased size of the organic linker. The increased tortuosity of electronic conduction pathways due to topological differences between MOF-14 and MOF-399 may also contribute to the differences observed using EIS.

The intrinsic porosity of the MOF analog films was demonstrated by cyclic voltammetry using redox probe characterization. The pores of the MOF-based films allowed Fc to diffuse to the Au substrate (current collector) and undergo redox reactions. Higher peak currents were observed for MOF-399 compared to MOF-14 analog films with the same number of deposition cycles due to the larger pore sizes of MOF-399 (e.g., 8.5 and $19.3 \mu \mathrm{A}$ for MOF-14 and MOF-399 8L samples, respectively). The observed redox reactions for Fc were not due to macroscopic or microscopic defects as large peak separation were observed ( $~ 0.55 \mathrm{~V}$ for MOF samples vs. $0.2 \mathrm{~V}$ for bare Au substrates). The dependence of the current on the sweep-rate in these measurements also deviated from what is predicted by the Randles-Sevcik equation. Asymmetry in the cyclic voltammograms due to screening of charged molecules is also consistent with the diffusion of $\mathrm{Fc}$ through the film pores. Future research will investigate the internal structure of these ultrathin conformal films using glancing angle synchrotron X-ray diffraction to determine crystallinity and to study the porosity indicated by the cyclic voltammetry measurements. 
Layer-by-layer deposition of these MOF analog films offers the control required to produce uniform films with nanoscale control of thicknesses for integration into electrochemical device architectures. The MOF-399-based films are promising for pseudo-solid-state electrolyte applications in microscale electrochemical energy storage devices. The lack of electronic conductivity impedes the leakage of electrons through the pseudo-solid-state electrolyte in devices, while the large porosity of the film suggests that a greater amount of liquid electrolyte can be incorporated into the film, maximizing the ionic conductivity and lowering the activation energy required for conduction. The MOF-14-based films could serve as tunable active electronic components by accommodating redox-active guest molecules within the demonstrated porosity to augment the intrinsic electronic conduction of the material.

\section{Supplementary Material}

Refer to Web version on PubMed Central for supplementary material.

\section{ACKNOWLEDGMENTS}

The authors acknowledge funding for this research from NSF-CHE 1508244 and NSF-MRI 1126462. MLO and MEA appreciate the Arnold and Mabel Beckman Foundation Scholars Program. MJM and MEA are grateful for the generous gift to Hope College from the Herbert H. and Grace A. Dow Foundation. AET, AJV, AJO, and MEA acknowledge support by the Schaap Endowed Fund for Undergraduate Research. KMC thanks the National Institute on Drug Abuse (DA045550) for support. JL, DA, and BD greatly appreciate the support of the work by the Office of Naval Research under award N00014-16-1-2164.

\section{REFERENCES}

(1). Zhang H; Nai J; Yu L; Lou XW Metal-Organic-Framework-Based Materials as Platforms for Renewable Energy and Environmental Applications. Joule 2017, 1, 77-107.

(2). Ma D; Li B; Zhou X; Zhou Q; Liu K; Zeng G; Li G; Shi Z; Feng S A Dual Functional MOF as a Luminescent Sensor for Quantitatively Detecting the Concentration of Nitrobenzene and Temperature. Chem. Commun. 2013, 49, 8964-8966.

(3). Eslava S; Zhang L; Esconjauregui S; Yang J; Vanstreels K; Baklanov MR; Saiz E Metal-Organic Framework ZIF-8 Films As Low- $\kappa$ Dielectrics in Microelectronics. Chem. Mater. 2013, 25, $27-$ 33.

(4). Stavila V; Talin AA; Allendorf MD MOF-Based Electronic and Opto-Electronic Devices. Chem. Soc. Rev. 2014, 43, 5994-6010. [PubMed: 24802763]

(5). Sun L; Campbell MG; Dincă M Electrically Conductive Porous Metal-Organic Frameworks. Angew. Chemie - Int. Ed. 2016, 55, 3566-3579.

(6). Choi KM; Jeong HM; Park JH; Zhang YB; Kang JK; Yaghi OM Supercapacitors of Nanocrystalline Metal-Organic Frameworks. ACS Nano 2014, 8, 7451-7457. [PubMed: 24999543]

(7). Nguyen TLA; Devic T; Mialane P; Rivière E; Sonnauer A; Stock N; Demir-Cakan R; Morcrette M; Livage C; Marrot J; et al. Reinvestigation of the MII (M = Ni, Co)/ TetraThiafulvaleneTetraCarboxylate System Using High-Throughput Methods: Isolation of a Molecular Complex and Its Single-Crystal-to-Single-Crystal Transformation to a TwoDimensional Coordination Polymer. Inorg. Chem. 2010, 49, 10710-10717. [PubMed: 20964449]

(8). Bai S; Liu X; Zhu K; Wu S; Zhou H Metal-Organic Framework-Based Separator for LithiumSulfur Batteries. Nat. Energy 2016, 1, 1-6.

(9). Wiers BM; Foo ML; Balsara NP; Long JR A Solid Lithium Electrolyte via Addition of Lithium Isopropoxide to a Metal-Organic Framework with Open Metal Sites. J. Am. Chem. Soc. 2011, 133, 14522-14525. [PubMed: 21877685] 
(10). Shen L; Wu H Bin Liu, F; Brosmer JL; Shen G; Wang, X.; Zink JI; Xiao Q; Cai M.; Wang G.; et al. Creating Lithium-Ion Electrolytes with Biomimetic Ionic Channels in Metal-Organic Frameworks. Adv. Mater. 2018, 30, 1-8.

(11). Park SS; Tulchinsky Y; Dincă M Single-Ion $\mathrm{Li}^{+}, \mathrm{Na}^{+}$, and $\mathrm{Mg}^{2+}$ Solid Electrolytes Supported by a Mesoporous Anionic Cu-Azolate Metal-Organic Framework. J. Am. Chem. Soc. 2017, 139, 13260-13263. [PubMed: 28880535]

(12). Zhu Y; Wang F; Liu L; Xiao S; Chang Z; Wu Y Composite of a Nonwoven Fabric with Poly(Vinylidene Fluoride) as a Gel Membrane of High Safety for Lithium Ion Battery. Energy Environ. Sci. 2013, 6, 618-624.

(13). Bates JB; Dudney NJ; Gruzalski GR; Zuhr RA; Choudhury A; Luck CF; Robertson JD Fabrication of Characterization of Amorphous Lithium Electrolyte Thin Films and Rechargeable Thin-Film Batteries. J. Power Sources 1993, 43, 103-110.

(14). Lin D; Liu Y; Cui Y Reviving the Lithium Metal Anode for High-Energy Batteries. Nat. Nanotechnol. 2017, 12, 194-206. [PubMed: 28265117]

(15). Ohnsorg ML; Beaudoin CK; Anderson ME Fundamentals of MOF Thin Film Growth via LiquidPhase Epitaxy: Investigating the Initiation of Deposition and the Influence of Temperature. Langmuir 2015, 31, 6114-6121. [PubMed: 26020573]

(16). Brower LJ; Gentry LK; Napier AL; Anderson ME Tailoring the Nanoscale Morphology of HKUST-1 Thin Films via Codeposition and Seeded Growth. Beilstein J. Nanotechnol. 2017, 8, 2307-2314. [PubMed: 29181287]

(17). Shekhah O; Wang H; Kowarik S; Schreiber F; Paulus M; Tolan M; Sternemann C; Evers F; Zacher D; Fischer RA; et al. Step-By-Step Route for the Synthesis of Metal-Organic Frameworks. J. Am. Chem. Soc. 2007, 129, 15118-15119. [PubMed: 18020338]

(18). Zhuang J-L; Kind M; Grytz C; Farr F; Diefenbach M; Tussupbayev S; Holthausen M; Terfort A Insight into the Oriented Growth of Surface-Attached Metal-Organic Frameworks: Surface Functionality, Deposition Temperature, and First Layer Order. J. Am. Chem. Soc. 2015, 137, 8237-8243. [PubMed: 26051709]

(19). Zacher D; Yusenko K; Bétard A; Henke S; Molon M; Ladnorg T; Shekhah O; Schüpbach B; Dea Losa Arcos T; Krasnopolski M; et al. Liquid-Phase Epitaxy of Multicomponent Layer-Based Porous Coordination Polymer Thin Films of [M(L)(P)0.5] Type: Importance of Deposition Sequence On the Oriented Growth. Chem. Eur. J. 2011, 17, 1448-1455. [PubMed: 21268147]

(20). Zhuang JL; Terfort A; Wöll C Formation of Oriented and Patterned Films of Metal-Organic Frameworks by Liquid Phase Epitaxy: A Review. Coord. Chem. Rev. 2016, 307, 391-424.

(21). Zacher D; Schmid R; Wöll C; Fischer R Surface Chemistry of Metal-Organic Frameworks at the Liquid-Solid Interface. Angew. Chemie - Int. Ed. 2011, 50, 176-199.

(22). Shekhah O; Liu J; Fischer RA; Wöll C; Woll C MOF Thin Films: Existing and Future Applications. Chem. Soc. Rev. 2011, 40, 1081-1106. [PubMed: 21225034]

(23). Li SSS; Shi W; Lu G; Li SSS; Loo SCJ; Huo F Unconventional Nucleation and Oriented Growth of ZIF-8 Crystals on Non-Polar Surface. Adv. Mater. 2012, 24, 5954-5958. [PubMed: 22936521]

(24). Shekhah O; Wang H; Zacher D; Fischer R; Wöll C Growth Mechanism of Metal-Organic Frameworks: Insights into the Nucleation by Employing a Step-by-Step Route. Angew. Chemie Int. Ed. 2009, 48, 5038-5041.

(25). Benson AS; Elinski MB; Ohnsorg ML; Beaudoin CK; Alexander KA; Peaslee GF; Deyoung PA; Anderson ME Metal-Organic Coordinated Multilayer Film Formation: Quantitative Analysis of Composition and Structure. Thin Solid Films 2015, 590, 103-110.

(26). Evans SD; Ulman A; Goppert-Berarducci KE; Gerenser LJ Self-Assembled Multilayers of $\omega$ Mercaptoalkanoic Acids: Selective Ionic Interactions. J. Am. Chem. Soc. 1991, 113, 5866-5868.

(27). Yang HC; Aoki K; Hong H; Sackett DD; Arendt MF; Yau S; Bell CM; Mallouk TE Growth and Characterization of Metal (II) Alkanebisphosphonate Multilayer Thin Films on Gold Surfaces. J. Am. Chem. Soc. 1993, 115, 11855-11862.

(28). Ansell MA; Zeppenfeld AC; Yoshimoto K; Cogan EB; Page CJ Self-Assembled CobaltDiisocyanobenzene Multilayer Thin Films. Chem. Mater. 1996, 8, 591-594. 
(29). Doron-Mor I; Hatzor A; Vaskevich A; van der Boom-Moav T; Shanzer A; Rubinstein I; Cohen H Controlled Surface Charging as a Depth-Profiling Probe for Mesoscopic Layers. Nature 2000, 406, 382-385. [PubMed: 10935629]

(30). Altman M; Shukla AD; Zubkov T; Evmenenko G; Dutta P; Van Der Boom ME Controlling Structure from the Bottom-up: Structural and Optical Properties of Layer-by-Layer Assembled Palladium Coordination-Based Multilayers. J. Am. Chem. Soc. 2006, 128, 7374-7382. [PubMed: 16734493]

(31). Neff GA; Helfrich MR; Clifton MC; Page CJ Layer-by-Layer Growth of Acentric Multilayers of $\mathrm{Zr}$ and Azobenzene Bis ( Phosphonate ): Structure, Composition, and Second-Order Nonlinear Optical Properties. Chem. Mater. 2000, 12, 2363-2371.

(32). Zhao S; Caruso F; Dähne L; Decher G; De Geest BG; Fan J; Feliu N; Gogotsi Y; Hammond PT; Hersam MC; et al. The Future of Layer-by-Layer Assembly: A Tribute to ACS Nano Associate Editor Helmuth Möhwald. ACS Nano 2019, 13, 6151-6169. [PubMed: 31124656]

(33). Hatzor A; Weiss PS Molecular Rulers for Scaling Down Nanostructures. Science. 2001, 291, 1019-1020. [PubMed: 11161210]

(34). Bent SF Heads or Tails: Which Is More Important in Molecular Self-Assembly? ACS Nano 2018, $1,10-12$.

(35). Claridge SA; Liao W-S; Thomas JC; Zhao Y; Cao HH; Cheunkar S; Serino AC; Andrews AM; Weiss PS From the Bottom up: Dimensional Control and Characterization in Molecular Monolayers. Chem. Soc. Rev. 2013, 42, 2725-2745. [PubMed: 23258565]

(36). Love JC; Estroff LA; Kriebel JK; Nuzzo RG; Whitesides GM Self-Assembled Monolayers of Thiolates on Metals as a Form of Nanotechnology. Chem. Rev. 2005, 105, 1103-1169. [PubMed: 15826011]

(37). Smith RK; Lewis PA; Weiss PS Patterning Self-Assembled Monolayers. Prog. Surf. Sci. 2004, $75,1-68$.

(38). Furukawa H; Go YB; Ko N; Park YK; Uribe-Romo FJ; Kim J; O’Keeffe M; Yaghi OM Isoreticular Expansion of Metal-Organic Frameworks with Triangular and Square Building Units and the Lowest Calculated Density for Porous Crystals. Inorg. Chem. 2011, 50, 9147-9152. [PubMed: 21842896]

(39). Dragässer A; Shekhah O; Zybaylo O; Shen C; Buck M; Wöll C; Schlettwein D Redox Mediation Enabled by Immobilised Centres in the Pores of a Metal-Organic Framework Grown by Liquid Phase Epitaxy. Chem. Commun. 2012, 48, 663-665.

(40). Liu J; Wächter T; Irmler A; Weidler PG; Gliemann H; Pauly F; Mugnaini V; Zharnikov M; Wöll C Electric Transport Properties of Surface-Anchored Metal-Organic Frameworks and the Effect of Ferrocene Loading. ACS Appl. Mater. Interfaces 2015, 7 (18), 9824-9830. [PubMed: 25875419]

(41). Hohman JN; Kim M; Bednar HR; Lawrence JA; McClanahand PD; Weiss PS Simple, Robust Molecular Self-Assembly on Germanium. Chem. Sci. 2011, 2, 1334-1343.

(42). Perng Y-C; Cho J; Sun SY; Membreno D; Cirigliano N; Dunn B; Chang JP Synthesis of Ion Conducting $\mathrm{Li}_{\mathrm{x}} \mathrm{Al}_{\mathrm{y}} \mathrm{Si}_{\mathrm{z}} \mathrm{O}$ Thin Films by Atomic Layer Deposition. J. Mater. Chem. A 2014, 2 (25), 9566-9573.

(43). Serino AC; Anderson ME; Saleh LMAA; Dziedzic RM; Mills H; Heidenreich LK; Spokoyny AM; Weiss PS Work Function Control of Germanium through Carborane-Carboxylic Acid Surface Passivation. ACS Appl. Mater. Interfaces 2017, 9, 34592-34596. [PubMed: 28920673]

(44). Loscutoff PW; Bent SF Reactivity of the Germanium Surface: Chemical Passivation and Functionalization. Annu. Rev. Phys. Chem. 2006, 57, 467-495. [PubMed: 16599818]

(45). Serino AC; Ko JS; Yeung MT; Schwartz JJ; Kang CB; Tolbert SH; Kaner RB; Dunn BS; Weiss PS Lithium-Ion Insertion Properties of Solution-Exfoliated Germanane. ACS Nano 2017, 11, 7995-8001. [PubMed: 28763196]

(46). Huey WLB; Goldberger JE Covalent Functionalization of Two-Dimensional Group 14 Graphane Analogues. Chem. Soc. Rev. 2018, 47, 6201-6223. [PubMed: 29881834]

(47). Dudney NJ Thin Film Micro-Batteries. Interface 2008, 17, 44-48. 
(48). Soni SK; Sheldon BW; Xiao X; Verbrugge MW; Ahn D; Haftbaradaran H; Gao H Stress Mitigation during the Lithiation of Patterned Amorphous Si Islands. J. Electrochem. Soc. 2012, 159 (1), A38-A43.

(49). Ji H; Hwang S; Kim K; Kim C; Jeong NC Direct in Situ Conversion of Metals into MetalOrganic Frameworks: A Strategy for the Rapid Growth of MOF Films on Metal Substrates. ACS Appl. Mater. Interfaces 2016, 8, 32414-32420. [PubMed: 27933821]

(50). Jeong NC; Samanta B; Lee CY; Farha OK; Hupp JT Coordination-Chemistry Control of Proton Conductivity in the Iconic Metal-Organic Framework Material HKUST-1. J. Am. Chem. Soc. 2012, 134, 51-54. [PubMed: 22148287]

(51). Talin AA; Centrone A; Ford AC; Foster ME; Stavila V; Haney P; Kinney RA; Szalai V; El Gabaly F; Yoon HP; et al. Tunable Electrical Conductivity in Metal-Organic Framework ThinFilm Devices. Science 2014, 343, 66-69. [PubMed: 24310609]

(52). Chen N; Reeja-Jayan B; Lau J; Moni P; Liu A; Dunn B; Gleason KK Nanoscale, Conformal Polysiloxane Thin Film Electrolytes for Three-Dimensional Battery Architectures. Mater. Horiz. 2015, 2, 309-314.

(53). Meek DW; Straub DK; Drago RS Transition Metal Ion Complexes of Dimethyl Sulfoxide. J. Am. Chem. Soc. 1960, 82, 6013-6016.

(54). Falcaro P; Ricco R; Doherty CM; Liang K; Hill AJ; Styles MJ MOF Positioning Technology and Device Fabrication. Chem. Soc. Rev. 2014, 43, 5513-5560. [PubMed: 24802634]

(55). Hendon CH; Walsh A Chemical Principles Underpinning the Performance of the Metal-Organic Framework HKUST-1. Chem. Sci. 2015, 6, 3674-3683. [PubMed: 28706713]

(56). Ahrenholtz SR; Epley CC; Morris AJ Solvothermal Preparation of an Electrocatalytic Metalloporphyrin MOF Thin Film and Its Redox Hopping Charge-Transfer Mechanism. J. Am. Chem. Soc. 2014, 136, 2464-2472. [PubMed: 24437480]

(57). Nadeem M; Akhtar MJ; Khan AY; Shaheen R; Haque MN Ac Study of 10\% Fe-Doped $\mathrm{La}_{0.65} \mathrm{Ca}_{0.35} \mathrm{MnO}_{3}$ Material by Impedance Spectroscopy. Chem. Phys. Lett. 2002, 366, 433-439.

(58). Jayasinghe GDLK; Dissanayake M a K. L.; Bandaranayake, P. W. S. K.; Souquet, J. L. Electronic to Ionic Conductivity of Glasses in the $\mathrm{Li}_{2} \mathrm{O}-\mathrm{V}_{2} \mathrm{O}_{5}-\mathrm{TeO}_{2}$ System. Solid State Ionics 1999, 121, 19-23.

(59). Nadeem M; Akhtar MJ; Khan AY Effects of Low Frequency near Metal-Insulator Transition Temperatures on Polycrystalline La0.65Ca0.35Mn1-yFeyO3 (Where $\mathrm{y}=0.05-0.10$ ) Ceramic Oxides. Solid State Commun. 2005, 134, 431-436.

(60). Lanfredi S; Saia PS; Lebullenger R; Hernandes AC Electric Conductivity and Relaxation in Fluoride, Fluorophosphate and Phosphate Glasses: Analysis by Impedance Spectroscopy. Solid State Ionics 2002, 146, 329-339.

(61). Heck R; Shekhah O; Zybaylo O; Weidler PG; Friedrich F; Maul R; Wenzel W; Wöll C Loading of Two Related Metal-Organic Frameworks (MOFs), [Cu2(Bdc)2(Dabco)] and [Cu2(Ndc)2(Dabco)], with Ferrocene. Polymers. 2011, 3, 1565-1574.

(62). Laoire CO; Plichta E; Hendrickson M; Mukerjee S; Abraham KM Electrochemical Studies of Ferrocene in a Lithium Ion Conducting Organic Carbonate Electrolyte. Electrochim. Acta 2009, $54,6560-6564$.

(63). Menshykau D; Compton RG Electrodes Modified with Electroinactive Layers: Distinguishing Through-Film Transport from Pinhole (Pore) Diffusion. Langmuir 2009, 25, 2519-2529. [PubMed: 19199745]

(64). Chailapakul O; Crooks RM Synthesis and Characterization of Simple Self-Assembling, Nanoporous Monolayer Assemblies: A New Strategy for Molecular Recognition. Langmuir 1993, 9, 884-888.

(65). Chailapakul O; Crooks RM Interactions between Organized, Surface-Confined Monolayers and Liquid-Phase Probe Molecules. 4. Synthesis and Characterization of Nanoporous Molecular Assemblies: Mechanism of Probe Penetration. Langmuir 1995, 11, 1329-1340.

(66). Johnson S; Bronowska A; Chan J; Evans D; Davies AG; Wälti C Redox-Induced Conformational Change in Mercaptoalkanoic Acid Multilayer Films. Langmuir 2012, 28, 6632-6637. [PubMed: 22448925] 

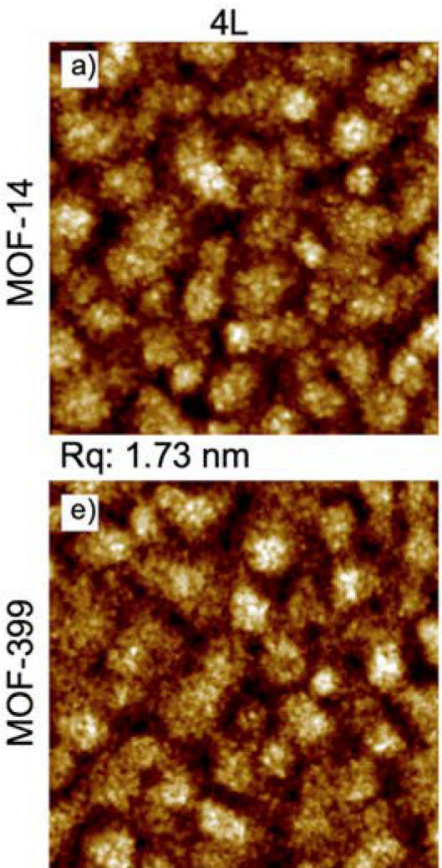

Rq: $1.70 \mathrm{~nm}$

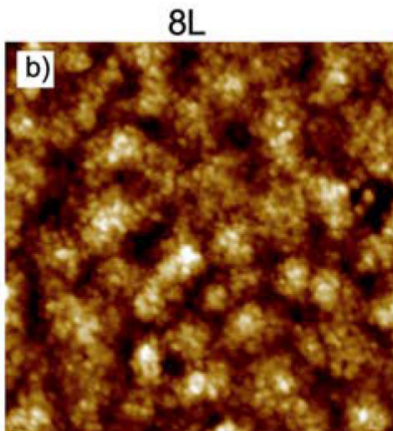

Rq: $1.67 \mathrm{~nm}$

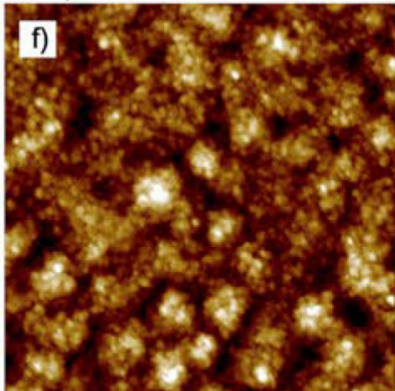

$\mathrm{Rq}: 1.63 \mathrm{~nm}$

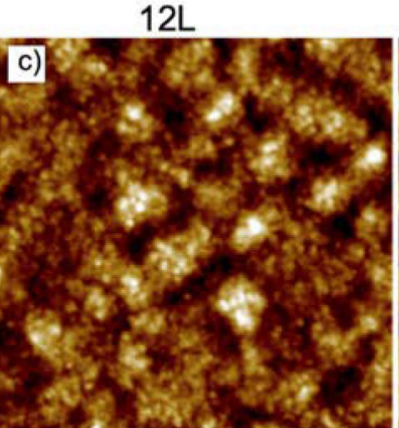

Rq: $1.59 \mathrm{~nm}$

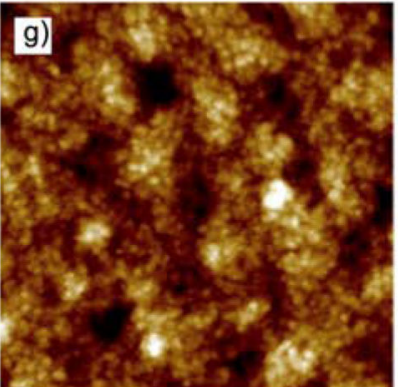

$\mathrm{Rq}: 1.53 \mathrm{~nm}$
$16 \mathrm{~L}$

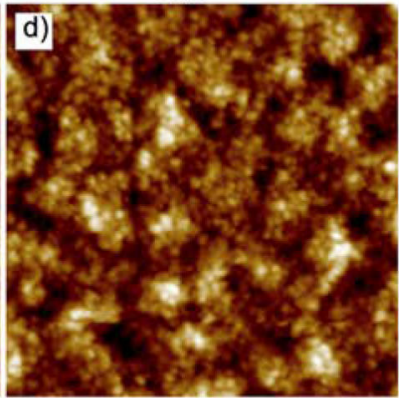

Rq: $1.57 \mathrm{~nm}$

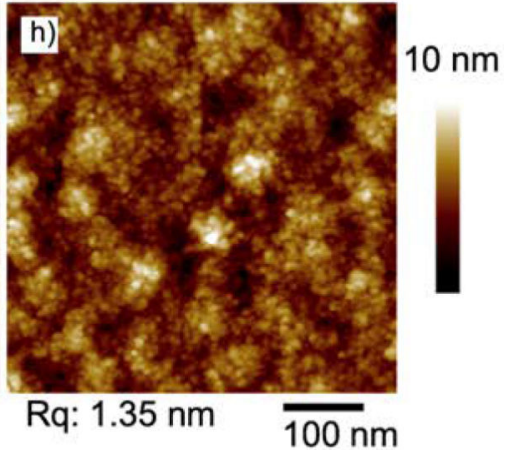

FIGURE 1.

Representative atomic force microscopy images $(500 \mathrm{~nm} \times 500 \mathrm{~nm})$ showing film growth for (a-d) MOF-14 and (e-h) MOF-399-based films anchored to Au substrates via a carboxylic acid-terminated self-assembled monolayers. Images were collected after every 4 layers of deposition (as indicated above the images). Below each image, the corresponding roughness $(\mathrm{Rq})$ is given. All images are set to the same $\mathrm{z}$-scale $(10 \mathrm{~nm})$ for visual comparison. 


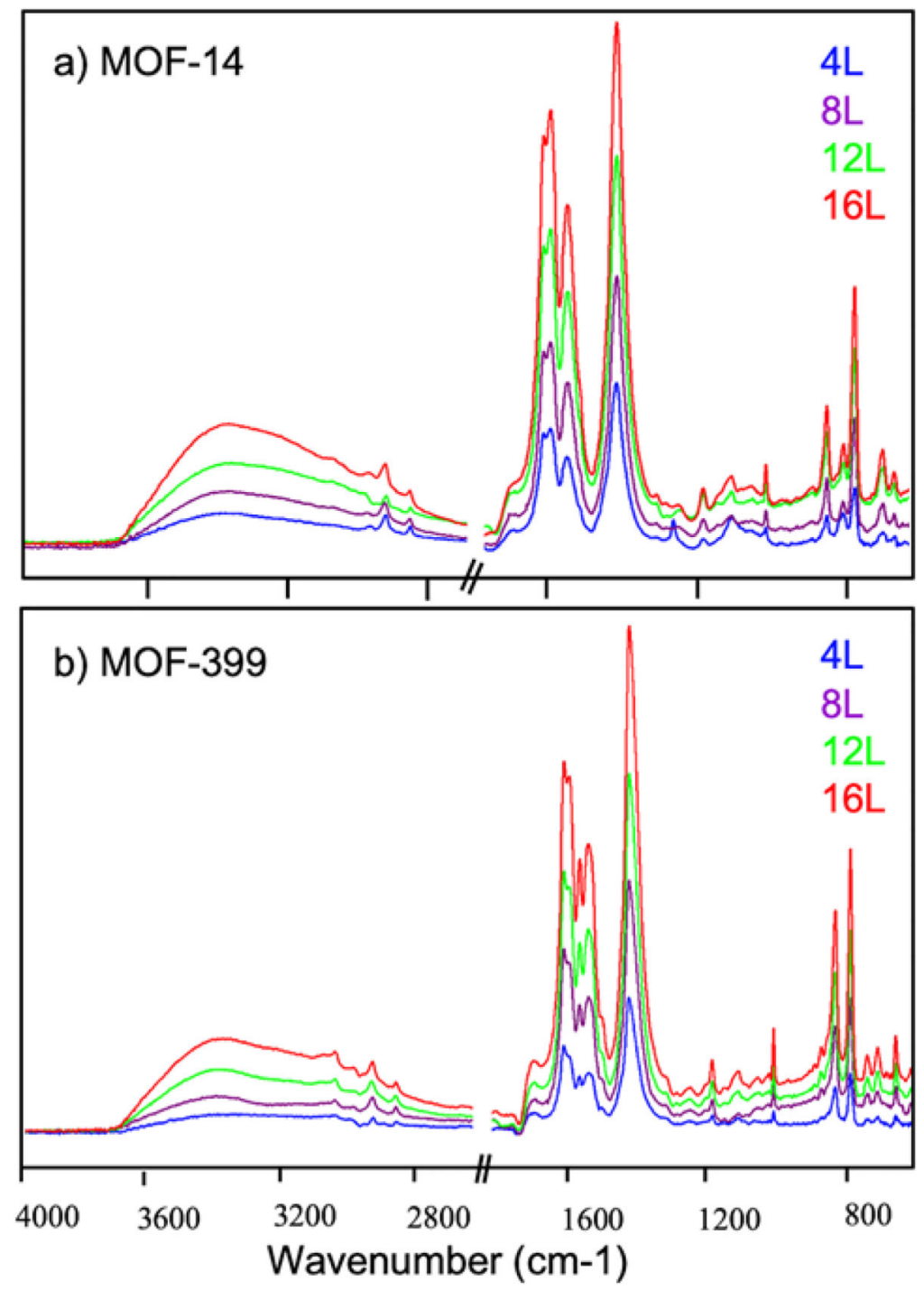

FIGURE 2.

Representative infrared spectra for (a) MOF-14- and (b) MOF-399-based films deposition on self-assembled monolayer films on Au. Spectra were collected after each 4 layers were deposited (as indicated in the legend on the right). 

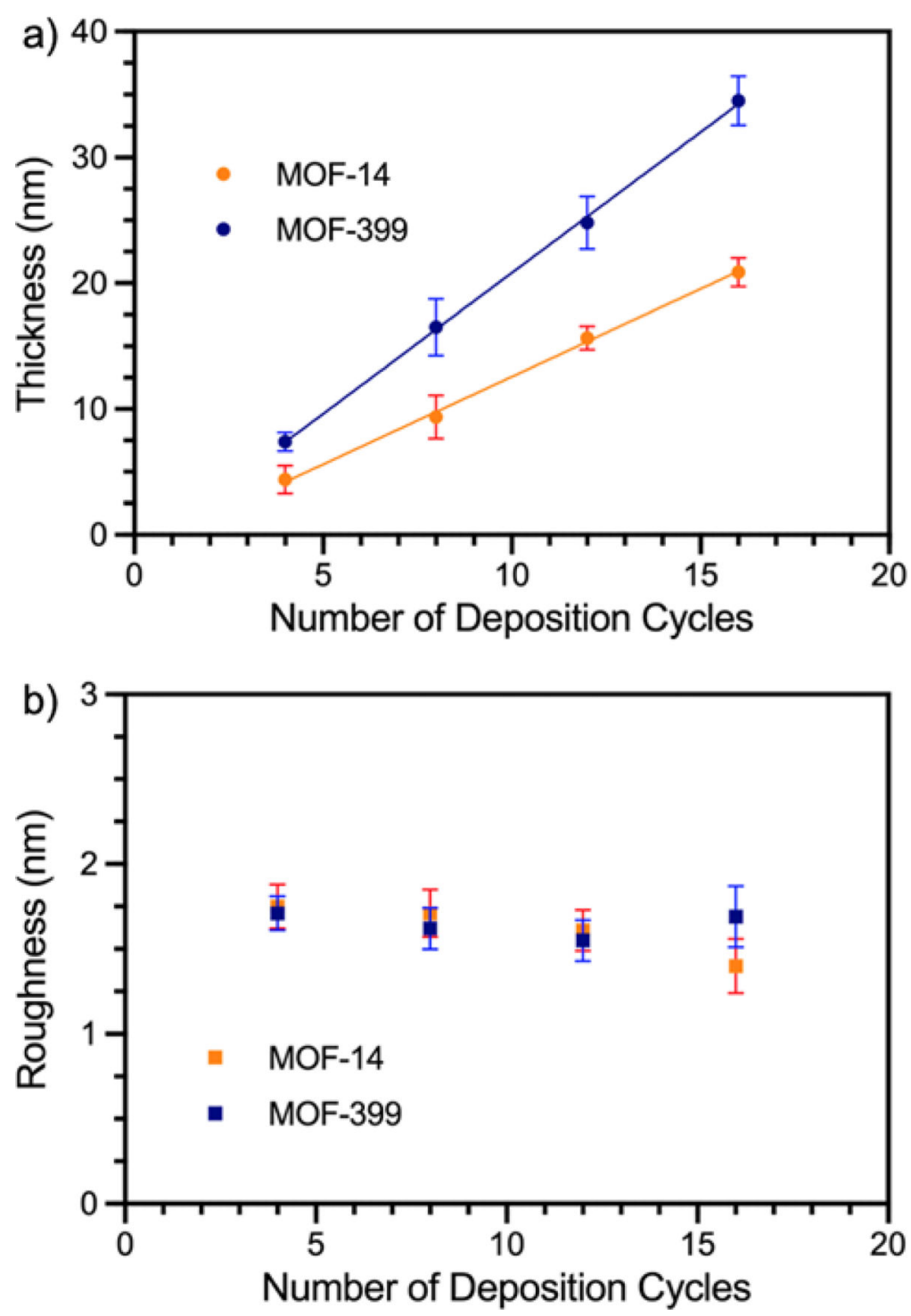

FIGURE 3.

The MOF (a) film thicknesses and (b) roughnesses were determined by atomic force microscopy. Thickness data for MOF-14 (orange symbols) and MOF-399 (blue symbols) thin-film analogs are plotted with linear fits yielding $\mathrm{y}=1.3955 \mathrm{x}-1.385, \mathrm{R}^{2}=0.9981$ and $\mathrm{y}$ $=2.2395 \mathrm{x}-1.58, \mathrm{R}^{2}=0.9992$ for MOF-14 and MOF-399, respectively. The film roughness $(\mathrm{Rq})$ for both MOF systems at all film thicknesses has standard deviations less than $10 \%$. 

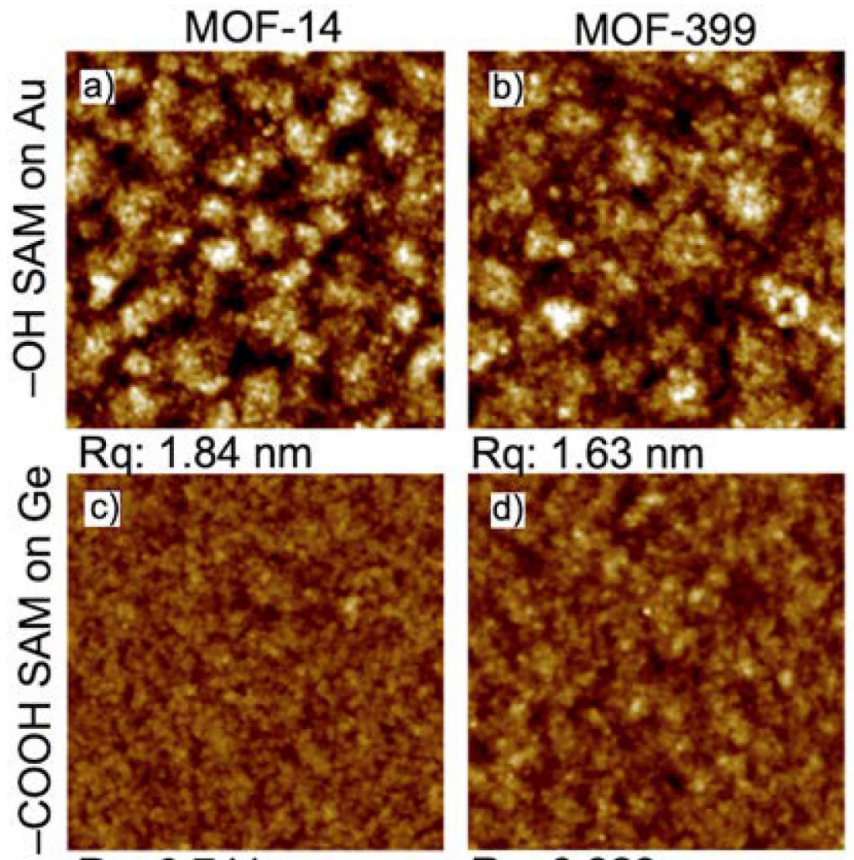

$\mathrm{Rq}: 1.63 \mathrm{~nm}$

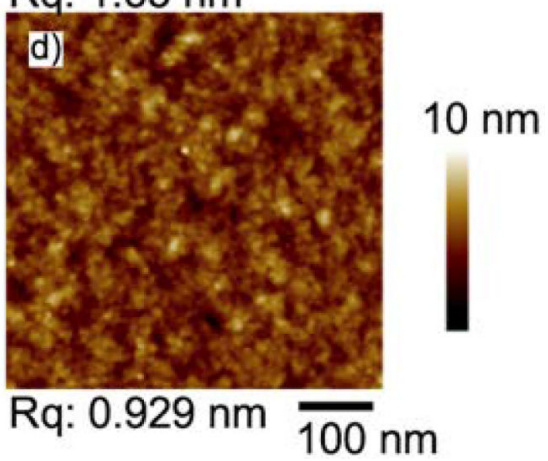

FIGURE 4.

Representative atomic force microscopy images $(500 \mathrm{~nm} \times 500 \mathrm{~nm}$ ) for (a) $4 \mathrm{~L}$ MOF-14- and (b) 4L MOF-399-based films anchored to a Au substrate via a hydroxyl-terminated selfassembled monolayer, and for (c) 4L MOF-14- and (d) 4L MOF-399-based films anchored to a $\mathrm{Ge}(100)$ substrate via a carboxylic-acid-terminated self-assembled monolayer film. Below each image, the corresponding roughness $(\mathrm{Rq})$ is given. All images are set to the same height scale $(10 \mathrm{~nm})$ for visual comparison. 

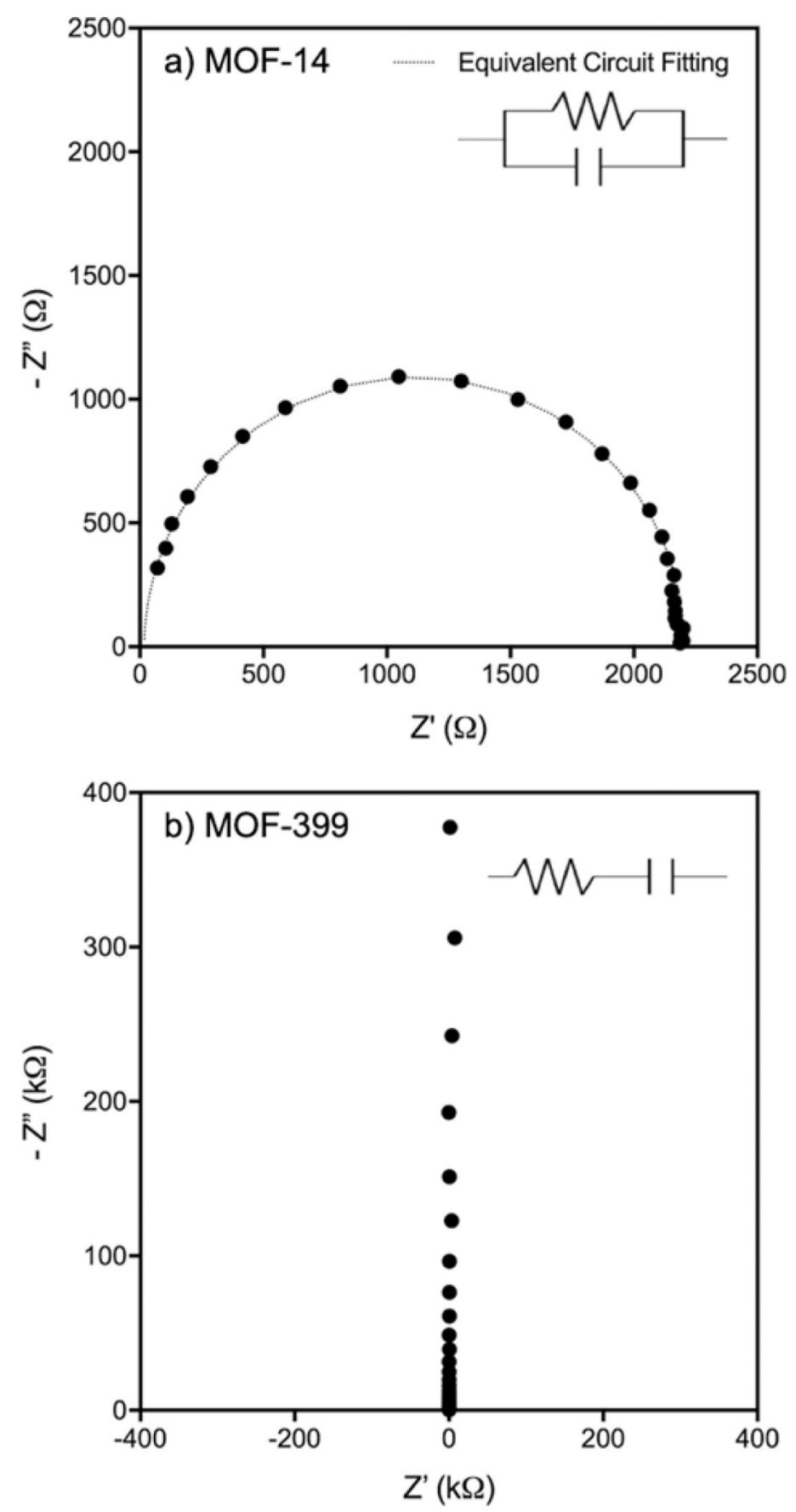

FIGURE 5.

Representative EIS spectra of (a) 8L MOF-14 and (b) 12L MOF-399 based films. Circuit schematics representative of the film electron transport behavior are inset with data. MOF-14 analog film data is fit to the equivalent circuit shown in (a). 

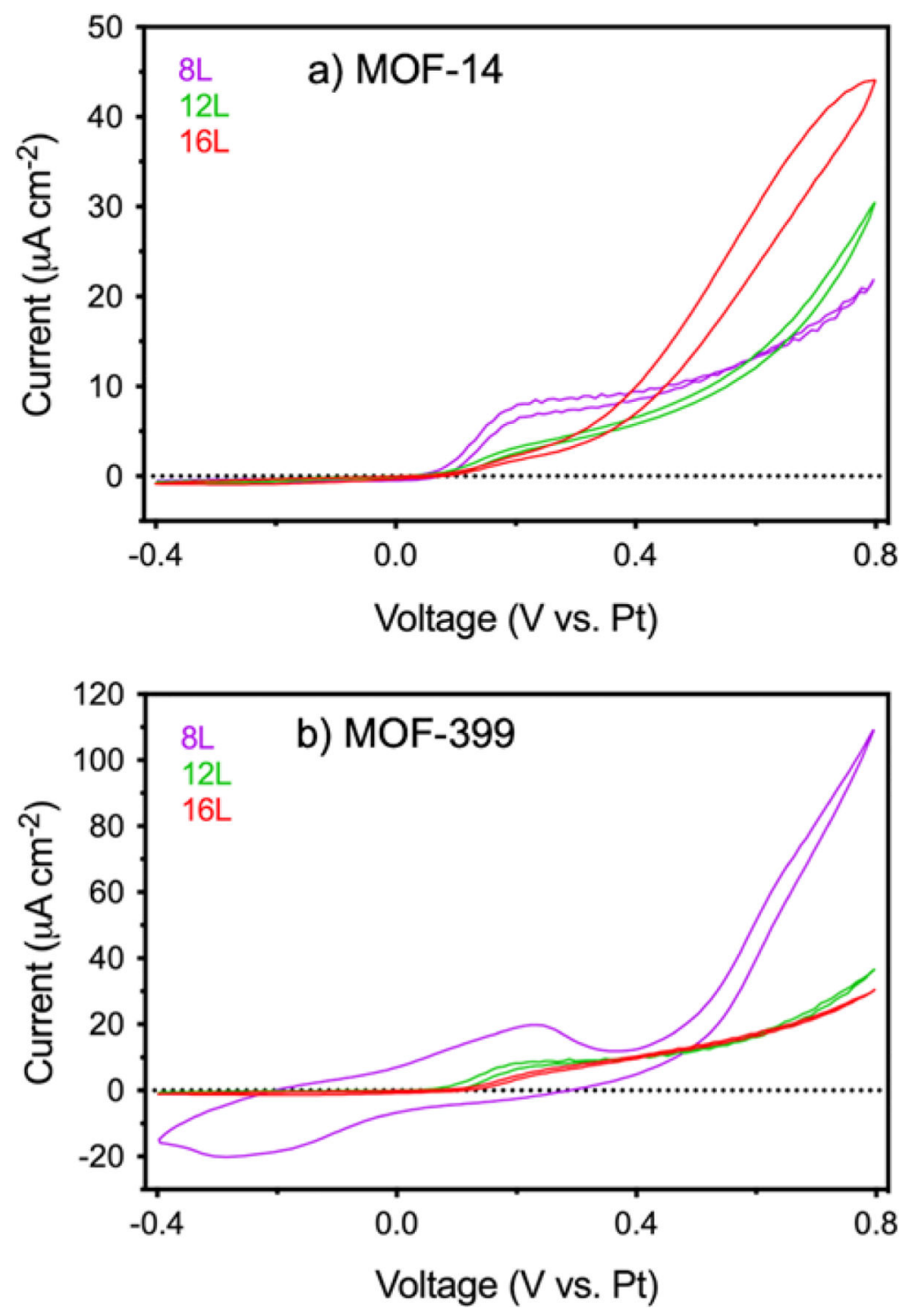

FIGURE 6.

Porosity of 8, 12, and 16L (a) MOF-14- and (b) MOF-399-based films in $10 \mathrm{mM} \mathrm{Fc|100}$ $\mathrm{mM}$ TBATFB PC at a sweep rate of $10 \mathrm{mV} \mathrm{s}^{-1}$. 